\title{
Role of age at asthma diagnosis in the asthma-obesity relationship
}

\author{
Shilpa Dogra $\mathrm{PhD}^{1,2}$, Joseph Baker $\mathrm{PhD}^{1,2}$, Chris I Ardern $\mathrm{PhD}^{2}$
}

\begin{abstract}
S Dogra, J Baker, CI Ardern. Role of age at asthma diagnosis in the asthma-obesity relationship. Can Respir J 2010;17(5):e97-e101.
\end{abstract}

OBJECTIVE: To determine whether age at asthma diagnosis has an impact on the previously described relationship between asthma and obesity. METHODS: Data were provided from Cycle 1.1 (2000/2001) of the Canadian Community Health Survey, a nationally representative health survey that included 6871 participants (2464 males and 4407 females) with asthma. Body mass index was used to categorize participants as normal weight $\left(18.5 \mathrm{~kg} / \mathrm{m}^{2}\right.$ to $\left.24.9 \mathrm{~kg} / \mathrm{m}^{2}\right)$, overweight $\left(25 \mathrm{~kg} / \mathrm{m}^{2}\right.$ to $\left.29.9 \mathrm{~kg} / \mathrm{m}^{2}\right)$ or obese $\left(30 \mathrm{~kg} / \mathrm{m}^{2}\right.$ or greater). Multivariate logistic regression analyses were used to estimate the odds of overweight and obesity by self-reported age at asthma diagnosis, after accounting for current age and other covariables. RESULTS: In fully adjusted models, males diagnosed with asthma during adolescence ( 12 to 20 years of age) were at elevated odds of obesity (OR 1.58; 95\% CI 1.03 to 2.43) compared with asthmatic patients diagnosed during childhood ( 0 to 11 years of age). Women diagnosed with asthma in mid life ( 21 to 44 years of age) and later life (45 to 64 years of age) were $43 \%$ (OR 1.43; $95 \%$ CI 1.08 to 1.90 ) and 56\% (OR 1.56; $95 \%$ CI 1.00 to 2.44 ) more likely to be obese than those diagnosed in childhood, respectively.

CONCLUSIONS: The impact of age at asthma diagnosis on the asthmaobesity relationship differed between males and females. However, the identification of high-risk groups of asthmatic patients may strengthen primary prevention strategies for obesity and related comorbidities at multiple levels of influence.

Key Words: Asthma; BMI; Obesity; Sex

\section{Le rôle de l'âge au diagnostic de l'asthme sur la relation entre l'asthme et l'obésité}

OBJECTIF : Déterminer si l'âge au diagnostic de l'asthme a des répercussions sur le lien déjà décrit entre l'asthme et l'obésité.

MÉTHODOLOGIE : Les données étaient tirées de l'Enquête sur la santé dans les collectivités canadiennes - cycle 1.1. (2000-2001), une enquête nationale représentative sur la santé qui incluait 6871 participants asthmatiques (2 464 hommes et 4407 femmes). L'indice de masse corporelle des participants a permis de les classer comme ayant un poids normal $\left(18,5 \mathrm{~kg} / \mathrm{m}^{2}\right.$ à $\left.24,9 \mathrm{~kg} / \mathrm{m}^{2}\right)$, faisant de l'embonpoint $\left(25 \mathrm{~kg} / \mathrm{m}^{2}\right.$ à $\left.29,9 \mathrm{~kg} / \mathrm{m}^{2}\right)$ ou obèses (30 kg/m ${ }^{2}$ ou plus). Les analyses de régression logistique multivariées ont permis d'évaluer la probabilité d'embonpoint ou d'obésité selon l'âge déclaré au diagnostic d'asthme, compte tenu de l'âge courant et d'autres covariables.

RÉSULTATS : Dans des modèles complètement ajustés, les hommes dont l'asthme avait été diagnostiqué pendant l'adolescence (12 à 20 ans) couraient un risque élevé d'obésité (RRR 1,58; 95 \% IC 1,03 à 2,43) par rapport aux patients asthmatiques diagnostiqués pendant l'enfance ( 0 à 11 ans). Les femmes dont l'asthme avait été diagnostiqué dans la force de l'âge (21 à 44 ans) et à l'âge mûr (45 à 64 ans) étaient $43 \%$ (RRR 1,43; $95 \%$ IC 1,08 à 1,90) et $56 \%$ (RRR 1,56; $95 \%$ IC 1,00 à 2,44) plus susceptibles, respectivement, d'être obèses que celles qui étaient diagnostiquées pendant l'enfance.

CONCLUSIONS : Les répercussions de l'âge au diagnostic d'asthme sur le lien entre l'asthme et l'obésité différaient entre les hommes et les femmes. Cependant, le dépistage de groupes de patients à haut risque pourrait renforcer les stratégies de prévention primaires d'obésité et de comorbidités connexes à de multiples niveaux d'influence.

to be conclusively established (5). There is some uncertainty regarding the temporal relationship between the two diseases because some studies $(3,4)$ have shown that obesity precedes asthma while other studies (6) suggest the opposite.

The complex association between asthma and obesity is underpinned by findings indicating that it varies according to sex, with a stronger association in females than in males $(4,6-9)$. In a population-based study by Chen et al (7), the prevalence of asthma was approximately twofold higher in women with a BMI of $30 \mathrm{~kg} / \mathrm{m}^{2}$ or more when compared with normal weight women, with no increase in risk noted for men (7). Similarly, in another cross-sectional analysis, the odds of obesity in adults was shown to be 1.9 times greater in women, and was not significantly associated in men (OR 1.1; $\mathrm{P}>0.05)$ (8). This phenomenon has been noted in children as well. A study (9) involving children five to six years of age showed a strong association between overweight and obesity with physician-diagnosed asthma in girls, but no association in boys.

Along with variations according to sex, the relationship between asthma and obesity has been shown to vary according between the two diseases, further research is required for this

${ }^{1}$ Lifespan Health and Performance Laboratory; ${ }^{2}$ School of Kinesiology and Health Science, York University, Toronto, Ontario

Correspondence: Dr Shilpa Dogra, School of Recreation Management and Kinesiology, 550 Main Street,Wolfville, Nova Scotia B4P 2R6.

Telephone 902-585-1566, fax 902-585-1702, e-mail shilpa.dogra@acadiau.ca 
to ethnicity (10) and allergic phenotype (11). Recently, the age at asthma diagnosis (AAD) has been shown to moderate the relationship between asthma and other chronic conditions such as cardiovascular disease $(12,13)$, and the development of allergic triggers (14). To date, AAD has not been studied in the context of the asthma-obesity relationship. Thus, the purpose of the present study was to characterize the role of AAD in the asthma-obesity relationship within a population-based sample of Canadian adults 20 to 64 years of age. Research (15) has shown that adolescents with asthma are particularly vulnerable to poor lifestyle habits such as alcohol use and smoking, and that risk behaviours tend to cluster (16). In addition, adolescents with chronic diseases - particularly asthma - have poor perceived health, which may further affect lifestyle habits (17). Therefore, we hypothesized that the odds of overweight and obesity would be highest in asthmatic patients diagnosed during adolescence because they may be more likely to adopt a physically inactive lifestyle and poor dietary habits.

\section{METHODS}

\section{Participants}

Data from the Canadian Community Health Survey (CCHS, cycle 1.1, 2000/2001), a nationally representative populationbased cross-sectional survey, were used. The CCHS collects information on the health status, health care use and health determinants of Canadians. Detailed information regarding survey sampling methods can be found in the CCHS user guide (18). All respondents provided informed consent before participation and were informed of the survey's objectives. Cycle 1.1 of the CCHS was selected because it included AAD as a variable and more recent cycles did not.

\section{Main outcome and exposure}

Self-reported height and weight were used to calculate BMI, which was subsequently used to categorize participants into the following three groups: normal weight $\left(18.5 \mathrm{~kg} / \mathrm{m}^{2}\right.$ to $\left.24.9 \mathrm{~kg} / \mathrm{m}^{2}\right)$, overweight $\left(25 \mathrm{~kg} / \mathrm{m}^{2}\right.$ to $\left.29.9 \mathrm{~kg} / \mathrm{m}^{2}\right)$ and obese $\left(30 \mathrm{~kg} / \mathrm{m}^{2}\right.$ to $\left.60 \mathrm{~kg} / \mathrm{m}^{2}\right)$. All participants were asked, "Do you have asthma?", participants who responded 'yes' were then asked, "How old were you when this was first diagnosed?" AAD was then used to categorize asthmatic patients into the following four AAD categories: childhood ( 0 to 11 years of age), adolescence (12 to 20 years of age), mid life (21 to 44 years of age) and later life (45 to 64 years of age).

\section{Main covariates and demographic variables}

Several demographic variables were used to characterize the the sample and were entered into multivariate models to assess their relationship with asthma. To ensure appropriate cell sizes for the analyses, some variables were modified such that two groups were collapsed to form one group.

Estimated energy expenditure was coded based on selfreported physical activities using a modified Minnesota Leisure Time Physical Activity Questionnaire. A physical activity index based on energy expediture was then created to classify participants as active $(1.5 \mathrm{kcal} / \mathrm{kg} /$ day or greater) or inactive (less than $1.5 \mathrm{kcal} / \mathrm{kg} /$ day). Daily fruit and vegetable consumption was reported and classified as low (less than five servings per day) or adequate (five or more servings per day). Lifetime cigarette consumption was classified as current smoker (daily smoker or occasional smoker) and nonsmoker. Participants were asked to specify their cultural or ethnic background, which was subsequently dichotomized into White and nonWhite. Socioeconomic status was assessed using education and income. Education levels were collapsed to form postsecondary education and no postsecondary education. Income was reported as low (less than $\$ 15,000 /$ year if one or two people resided in a given household; less than $\$ 20,000 /$ year if three or four people; and less than $\$ 30,000 /$ year if five or more people) and mid to high income $(\$ 15,000$ /year or greater if one or two people resided in a given household; $\$ 20,000 /$ year or greater if three or four people; and $\$ 30,000 /$ year or greater if five or more people) as per the threshold values used by Statistics Canada..

\section{Statistical analysis}

All data were analyzed using SPSS version 14.0 (SPSS Inc, USA), with $t$ tests and $\chi^{2}$ tests performed for all covariates and demographic variables. Multivariate logistic regression models were produced using the 'Enter method' (forced entry) such that all exposure variables and covariates that were significant at the bivariate level were entered into the model in a single step. Crude and adjusted ORs with corresponding 95\% CIs were calculated for overweight compared with normal weight, and obese compared with normal weight (an OR of 1.0 served as the reference category). A master weight was applied to the data to ensure that the sample was representative of the Canadian population - this weight is available in the CCHS file and must be applied to make meaningful estimates of population parameters. The response rate of the CCHS was $80 \%$, which varied by province (18).

\section{RESULTS}

The overall prevalence of asthma in the sample was $7.8 \%$. There were 6871 asthmatic patients in the sample (2462 males and 4407 females). Sample characteristics for each AAD group stratified according to sex are summarized in Table 1. Significant differences were noted for all variables; therefore, all were included as covariates in the mulitvariate analysis.

The percentage of obese asthmatic patients increased progressively from the childhood AAD group to the later-life AAD group (Figure 1). The $\chi^{2}$ for both males and females were significant for both overweight (male $\chi^{2}=14.3, \mathrm{P}=0.003$; female $\left.\chi^{2}=76.5, \mathrm{P}<0.0001\right)$ and obese $\left(\right.$ male $\chi^{2}=25.3, \mathrm{P}<0.0001$; female $\left.\chi^{2}=81.6, \mathrm{P}<0.0001\right)$ compared with normal weight.

Table 2 summarizes the results of the logistic regression analyses. After adjusting for all covariates and demographic variables, males diagnosed with asthma in adolescence were $58 \%$ more likely to be obese than those diagnosed in childhood. On the other hand, females diagnosed with asthma in mid or later life were $43 \%$ and $56 \%$ more likely to be obese than those diagnosed with asthma in childhood, respectively, after adjusting for all other factors.

The covariates entered into the model were also significantly associated with obesity. Asthmatic patients who were physically active were less likely to be obese than inactive asthmatic individuals (male OR $0.71,95 \%$ CI 0.52 to 0.97 ; female OR $0.67,95 \%$ CI 0.54 to 0.83 ). Asthmatic patients who consumed less than five servings of fruits and vegetables per day were more likely to be obese than those consuming more than five servings of fruits and vegetables per day (male OR $1.9,95 \%$ CI 1.3 to 2.6 ; female OR $1.3,95 \%$ CI 1.0 to 1.6). 
TABLE 1

Characteristics of males and females according to age at asthma diagnosis category

\begin{tabular}{|c|c|c|c|c|c|c|c|c|}
\hline & \multicolumn{4}{|c|}{ Males } & \multicolumn{4}{|c|}{ Females } \\
\hline & Childhood & Adolescence & Mid life & Later life & Childhood & Adolescence & Mid life & Later life \\
\hline n (unweighted) & 901 & 484 & 793 & 286 & 962 & 1055 & 1806 & 584 \\
\hline Current age, years (mean $\pm \mathrm{SD}$ ) & $33.9 \pm 10.7$ & $33.2 \pm 10.8$ & $41.2 \pm 9.4^{*}$ & $56.6 \pm 5.0^{*}$ & $33.5 \pm 11.3$ & $31.9 \pm 10.4^{*}$ & $42.4 \pm 9.2^{*}$ & $56.8 \pm 5.0^{*}$ \\
\hline \multicolumn{9}{|l|}{ Physical activity index ${ }^{\dagger}$} \\
\hline Active & 52.1 & 48.8 & 44.6 & $38.1^{*}$ & 45.7 & 46.7 & $38.2^{*}$ & $38.6^{*}$ \\
\hline Inactive & 47.9 & 51.2 & 55.4 & $61.9 *$ & 54.3 & 53.3 & $61.8^{*}$ & $61.4^{\star}$ \\
\hline \multicolumn{9}{|l|}{ Daily fruit and vegetable consumption } \\
\hline Low & 67.5 & $70.8^{*}$ & $70.9 *$ & 69.2 & 57.0 & 54.0 & 61.4 & 57.6 \\
\hline Adequate & 32.5 & $29.2^{\star}$ & $29.1^{\star}$ & 30.8 & 43.0 & 46.0 & 38.6 & 42.4 \\
\hline \multicolumn{9}{|l|}{ Smoking status } \\
\hline Current & 34.0 & $42.0^{*}$ & 31.3 & $21.3^{*}$ & 30.5 & 35.9 & 32.2 & $23.4^{*}$ \\
\hline Nonsmoker & 66.0 & $58.0 *$ & 68.7 & $78.7^{\star}$ & 69.5 & 64.1 & 67.8 & $76.6^{\star}$ \\
\hline \multicolumn{9}{|l|}{ Income } \\
\hline Low & 7.5 & 11.9 & $14.5^{\star}$ & $16.9^{*}$ & 13.7 & 16.3 & 15.0 & $20.1^{*}$ \\
\hline Mid to high & 92.5 & 88.1 & $85.5^{\star}$ & $83.1^{\star}$ & 86.3 & 83.7 & 85.0 & $79.9^{*}$ \\
\hline \multicolumn{9}{|l|}{ Education } \\
\hline No postsecondary & 34.1 & 37.2 & $43.7^{*}$ & $50.4^{*}$ & 31.0 & 33.8 & $40.7^{*}$ & $57.2^{*}$ \\
\hline Postsecondary & 65.9 & 62.8 & $56.3^{*}$ & $49.6^{*}$ & 69.0 & 66.2 & $59.3^{*}$ & $42.8^{\star}$ \\
\hline \multicolumn{9}{|l|}{ Ethnicity } \\
\hline White & 90.2 & 89.0 & $87.1^{\star}$ & 90.5 & 86.7 & 91.1 & 88.7 & 85.3 \\
\hline Non-White & 9.8 & 11.0 & $12.9^{*}$ & 9.5 & 13.3 & 8.9 & 11.3 & 14.7 \\
\hline
\end{tabular}

Data presented as \% unless otherwise indicated. Between group differences were assessed using $\chi^{2}$ analysis for categorical variables and tests for continuous variables $^{*} P \leq 0.05$ compared with childhood: Childhood 0 to 11 years of age, Adolescence 12 to 20 years of age, Mid Life 21 to 44 years of age, Later life 45 to 64 years of age; ${ }^{\dagger}$ Active $\geq 1.5 \mathrm{kcal} / \mathrm{kg} /$ day, inactive $<1.5 \mathrm{kcal} / \mathrm{kg} /$ day

Current smokers were less likely to be obese than nonsmokers (male OR 0.45, 95\% CI 0.32 to 0.63; female OR 0.71, 95\% CI 0.56 to 0.89 ). Ethnicity was significantly associated with obesity in males only such that Whites were more likely to be obese than non-Whites (OR 2.9, 95\% CI 1.6 to 5.1). Finally, the odds of obesity were higher in low income than in mid- to high-income asthmatic patients in females only (OR 1.4, 95\% CI 1.0 to 1.8$)$.

\section{DISCUSSION}

In the present study, we found a significant association between AAD and obesity; however, the association differed according to sex such that males were at increased odds of obesity when diagnosed with asthma in adolescence, while females were at increased odds of obesity when diagnosed with asthma after 20 years of age.

The increased odds of obesity in males diagnosed with asthma during adolescence is consistent with our original hypothesis. There are at least three possible explanations for this relationship. First, there is a significant risk of declining physical activity patterns in adolescents 15 to 18 years of age (19). Furthermore, adolescents with asthma have been shown to be less active and less physically fit than their age-matched peers (20). Second, adolescents diagnosed with asthma are more likely to engage in risk-taking behaviours such as smoking and alcohol consumption $(15,16,21,22)$. Third, adolescents with chronic disease have been shown to have lower self-perceived health, which in turn, has been shown to correlate with poor nutritional habits, smoking and physical inactivity (17). It thereby follows that an adolescent diagnosed with asthma may be more likely to adopt a sedentary and unhealthy lifestyle, which would impact their future BMI and general health.

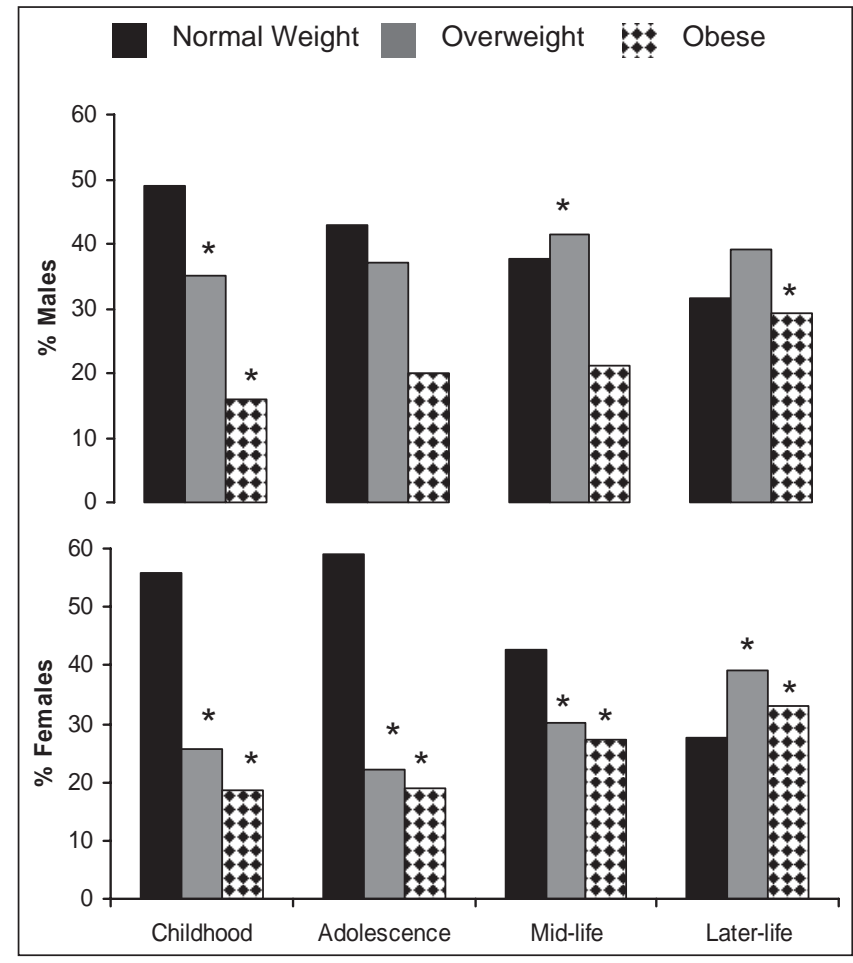

Figure 1) Distribution (\%) of body mass index according to age at asthma onset for males and females. Childhood 0 to 11 years of age; Adolescence 12 to 20 years of age; Mid life 21 to 44 years of age; Later life 45 to 64 years of age. Normal weight $18.5 \mathrm{~kg} / \mathrm{m}^{2}$ to $24.9 \mathrm{~kg} / \mathrm{m}^{2}$; Overweight $25 \mathrm{~kg} / \mathrm{m}^{2}$ to $29.9 \mathrm{~kg} / \mathrm{m}^{2}$; Obese $30 \mathrm{~kg} / \mathrm{m}^{2}$ to $60 \mathrm{~kg} / \mathrm{m}^{2}$. $* \mathrm{P}<0.05$ compared with normal weight within each age at asthma diagnosis group 


\section{TABLE 2}

Crude and adjusted ORs for overweight and obesity according to age at asthma diagnosis category

\begin{tabular}{|c|c|c|c|c|}
\hline \multirow[b]{2}{*}{ Males } & \multicolumn{2}{|c|}{ Crude } & \multicolumn{2}{|c|}{ Adjusted } \\
\hline & OR & $95 \% \mathrm{Cl}$ & OR & $95 \% \mathrm{Cl}$ \\
\hline \multicolumn{5}{|l|}{ Overweight } \\
\hline Childhood & 1.00 & Reference & 1.00 & Reference \\
\hline Adolescence & 1.23 & 0.91-1.65 & 1.30 & $0.93-1.82$ \\
\hline Mid life & $1.55^{\star}$ & $1.19-2.02$ & 1.09 & $0.80-1.50$ \\
\hline Later life & $1.72^{\star}$ & $1.16-2.55$ & 0.73 & $0.44-1.23$ \\
\hline \multicolumn{5}{|l|}{ Obese } \\
\hline Childhood & 1.00 & Reference & 1.00 & Reference \\
\hline Adolescence & 1.44 & $1.00-2.08$ & $1.58^{*}$ & $1.03-2.43$ \\
\hline Mid life & $1.73^{\star}$ & $1.25-2.40$ & 1.26 & $0.85-1.86$ \\
\hline Later life & $2.84^{\star}$ & $1.82-4.42$ & 1.29 & $0.72-2.34$ \\
\hline \multicolumn{5}{|l|}{ Females } \\
\hline \multicolumn{5}{|l|}{ Overweight } \\
\hline Childhood & 1.00 & Reference & 1.00 & Reference \\
\hline Adolescence & 0.81 & $0.61-1.07$ & 0.86 & $0.64-1.16$ \\
\hline Mid life & $1.52^{\star}$ & $1.20-1.93$ & 1.13 & $0.87-1.48$ \\
\hline Later life & $3.08^{\star}$ & $2.21-4.28$ & 1.43 & $0.94-2.17$ \\
\hline \multicolumn{5}{|l|}{ Obese } \\
\hline Childhood & 1.00 & Reference & 1.00 & Reference \\
\hline Adolescence & 0.97 & $0.72-1.31$ & 1.04 & $0.75-1.42$ \\
\hline Mid life & $1.91^{\star}$ & $1.48-2.48$ & $1.43^{*}$ & $1.08-1.90$ \\
\hline Later life & $3.60^{*}$ & $2.53-5.12$ & $1.56^{*}$ & $1.01-2.44$ \\
\hline
\end{tabular}

Adjusted models include age, physical activity level, fruit and vegetable consumption, smoking status, income, education and race as covariates. Childhood 0 to 11 years of age; Adolescence 12 to 20 years of age; Mid life 21 to 44 years of age; Later life 45 to 64 years of age. ${ }^{*} P \leq 0.05$

In contrast to our original hypothesis, the association of $\mathrm{AAD}$ and obesity in females was the opposite of that seen in males. Although sex differences are common in asthma-obesity research (7-9), these findings warrant consideration within the context of behaviours such as physical activity. Male adolescents have more favourable physical activity patterns than females, especially with regard to regular vigorous activity and strengthening exercises; these differences are particularly pronounced in the 12 to 16 years age group (19).Thus, the diagnosis of asthma in females before the age of 20 years may have little or no impact on the development of lifestyle or activity habits because all female adolescents tend to be less active. Therefore, it is plausible that the diagnosis of a chronic disease such as asthma interferes with the development of activity and lifestyle behaviours of females in adulthood to a greater extent than during adolescence.

Although the main effects demonstrated in the present study are not consistent, the possibility of another contributor to the asthma-obesity relationship is important. AAD may only explain a small portion of the link between these two diseases; however, it provides a unique opportunity for physicians to target high-risk populations such as adolescent males and adult females diagnosed with asthma. This is precisely the area that can benefit from initiatives such as 'Exercise is Medicine' (23) - a partnership between the American College of Sports Medicine and the American Medical Association. If physicians are able to intervene with effective exercise plans for these asthmatic individuals, the risk of developing obesity and subsequent comorbidities may be mitigated. Although all asthmatic patients should appreciate the impact of the above mentioned initiative, high-risk groups that are identified according to AAD should become a priority for targeted screening. Given that $64 \%$ of asthmatic patients are either overweight or obese (24), primary prevention initiatives are likely to benefit both chronic conditions.

\section{Limitations}

As with most epidemiological investigations, limitations of the study design and analysis must be considered. First, although $\mathrm{AAD}$ was self-reported and, consequently, subject to recall bias, our intentional use of wide age categories makes it less likely that misclassification bias could account for our results. Second, overweight and obesity were based on self-reported height and weight (BMI) as a measure of overall adiposity. Nonetheless, because the association between asthma and BMI is more consistent than that of skinfold measurements (for children) (25), and the relationship between asthma and obesity as measured by BMI or waist circumference are similar (7), we are confident that BMI was a sufficient measure. Because the database did not contain information regarding birth weight, childhood body composition or weight status at AAD, a lifetime adiposity measure could not be derived. Third, although the CCHS does not contain information regarding asthma severity or lung function (which may influence the risk of obesity), our results are generalizable to individuals with mild, moderate and severe asthma. Fourth, because the CCHS is cross-sectional, cause and effect could not be determined. Finally, while chronic obstructive pulmonary disease, smoking and asthma are highly inter-related, all analyses were adjusted for current smoking status, with only $3.2 \%$ of asthmatic patients found to have chronic obstructive pulmonary disease. These individuals would be spread over the various AAD categories.

\section{CONCLUSION}

AAD offers an alternative explanation for observed sex differences in the obesity rates among asthmatic patients. As such, exercise and lifestyle counselling should be considered an important component of asthma management action plans prescribed by physicians, especially in high-risk groups. Future research is necessary to clarify the role of AAD as a contributor to the asthma-obesity relationship by using longitudinal data, so that obesity and asthma time points can be established and the true impact of $\mathrm{AAD}$ can be determined.

ACKNOWLEDGEMENTS: While the research and analysis were based on data from Statistics Canada, the opinions expressed do not represent the views of Statistics Canada. The authors thank the staff at the Statistics Canada Research Data Centre at the University of Toronto (Toronto, Ontario) for their administrative support.

\section{REFERENCES}

1. Statistics Canada, 2007. Asthma, by age group and sex. <http://www40.statcan.gc.ca/101/cst01/health49b-eng.htm> (Accessed on August 26, 2010).

2. Chen Y, Johansen H, Thillaiampalam S, Sambell C. Asthma. Health Reports 2005;16:43-6.

3. Camargo CA Jr, Weiss ST, Zhang S, Willett WC, Speizer FE. Prospective study of body mass index, weight change, and risk of adult-onset asthma in women. Arch Intern Med 1999;159:2582-8. 
4. Nystad W, Meyer HE, Nafstad P, Tverdal A, Engeland A. Body mass index in relation to adult asthma among 135,000 Norwegian men and women. Am J Epidemiol 2004;160:969-76.

5. Shore SA. Obesity and asthma: Cause for concern. Curr Opin Pharmacol 2006;6:230-6.

6. Hasler G, Gergen PJ, Ajdacic V, et al. Asthma and body weight change: A 20-year prospective community study of young adults. Int J Obes (Lond) 2006;30:1111-8.

7. Chen Y, Rennie D, Cormier Y, Dosman J. Sex specificity of asthma associated with objectively measured body mass index and waist circumference: The Humboldt study. Chest 2005;128:3048-54

8. Chen Y, Dales R, Tang M, Krewski D. Obesity may increase the incidence of asthma in women but not in men: Longitudinal observations from the Canadian National Population Health Surveys. Am J Epidemiol 2002;155:191-7.

9. von Kries R, Hermann M, Grunert VP, von Mutius E. Is obesity a risk factor for childhood asthma? Allergy 2001;56:318-22.

10. Kim S, Camargo CA Jr. Sex-race differences in the relationship between obesity and asthma: The behavioral risk factor surveillance system, 2000. Ann Epidemiol 2003;13:666-73.

11. Chen Y, Dales R, Jiang Y. The association between obesity and asthma is stronger in nonallergic than allergic adults. Chest 2006;130:890-5.

12. Onufrak S, Abramson J, Vaccarino V. Adult-onset asthma is associated with increased carotid atherosclerosis among women in the Atherosclerosis Risk in Communities (ARIC) study. Atherosclerosis 2007;195:129-37.

13. Dogra S, Ardern CI, Baker J. The relationship between age of asthma onset and cardiovascular disease in Canadians. J Asthma 2007;44:849-54.

14. Sarafino EP, Gates M, DePaulo D. The role of age at asthma diagnosis in the development of triggers of asthma episodes. J Psychosom Res 2001;51:623-8.
15. Forero R, Bauman A, Young L, Booth M, Nutbeam D. Asthma, health behaviors, social adjustment, and psychosomatic symptoms in adolescence. J Asthma 1996;33:157-64.

16. Bender BG. Risk taking, depression, adherence, and symptom control in adolescents and young adults with asthma. Am J Respir Crit Care Med 2006;173:953-7.

17. Tremblay S, Dahinten S, Kohen D. Factors related to adolescents' self-perceived health. Health Rep 2003;14(Suppl):7-16.

18. CCHS, cycle 1.1 (Canadian Community Health Survey), 2001. $<$ http://www.statcan.ca/english/concepts/health/> (Accessed on August 16, 2010).

19. Caspersen CJ, Pereira MA, Curran KM. Changes in physical activity patterns in the United States, by sex and cross-sectional age. Med Sci Sports Exerc 2000;32:1601-9.

20. Counil FP, Karila C, Varray A, Guillaumont S, Voisin M, Préfaut C. Anaerobic fitness in children with asthma: Adaptation to maximal intermittent short exercise. Pediatr Pulmonol 2001;31:198-204.

21. Precht DH, Keiding L, Madsen M. Smoking patterns among adolescents with asthma attending upper secondary schools: A community-based study. Pediatrics 2003;111:562-8.

22. Zbikowski SM, Klesges RC, Robinson LA, Alfano CM. Risk factors for smoking among adolescents with asthma. J Adolesc Health 2006;30:279-87.

23. Exercise is MedicineTM. American College of Sport Medicine and American Medical Association. <http://www.exerciseismedicine. org/index2.htm> (Accessed on August 29, 2009).

24. Lavoie KL, Bacon SL, Labrecque M, Cartier A, Ditto B. Higher BMI is associated with worse asthma control and quality of life but not asthma severity. Respir Med 2006;100:648-57.

25. Figueroa-Muñoz JI, Chinn S, Rona RJ. Association between obesity and asthma in 4-11 year old children in the UK. Thorax 2001;56:133-7. 


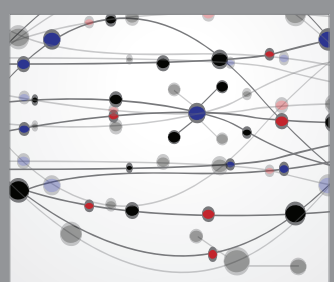

The Scientific World Journal
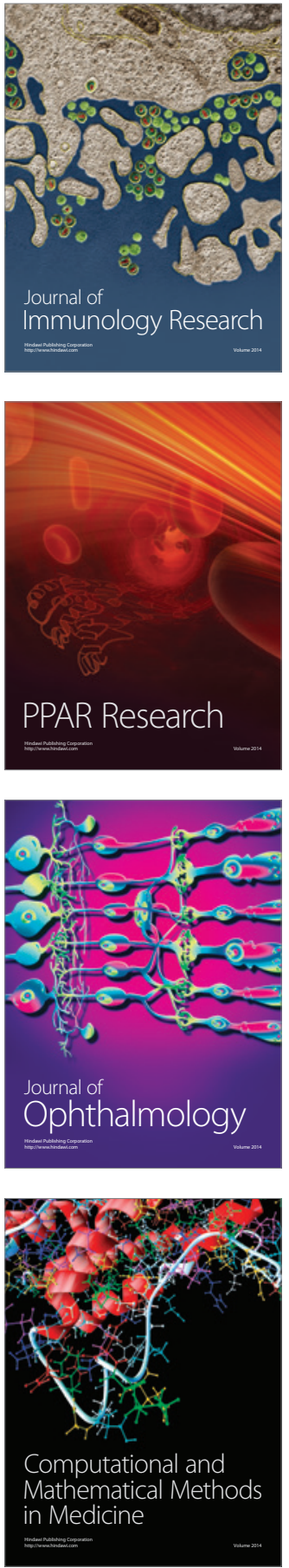

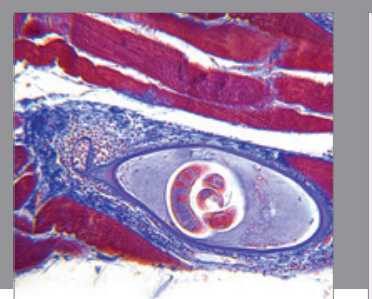

Gastroenterology Research and Practice

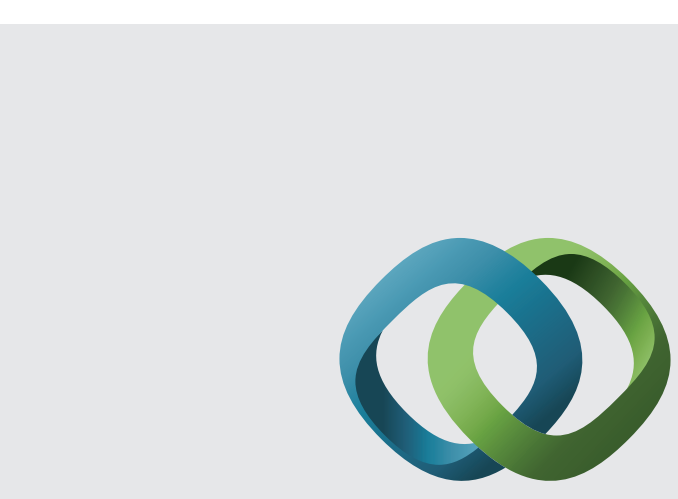

\section{Hindawi}

Submit your manuscripts at

http://www.hindawi.com
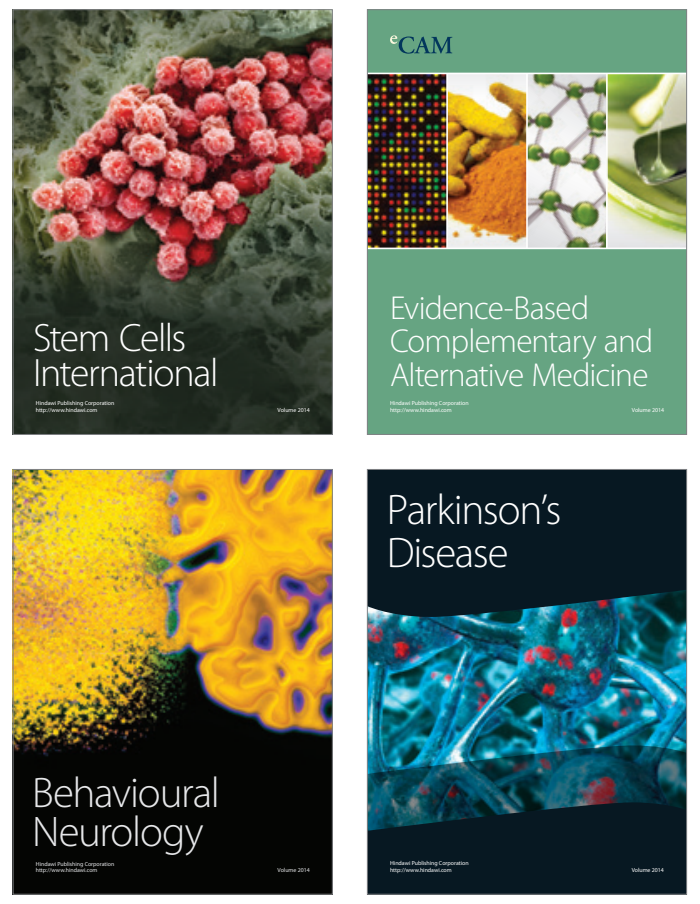
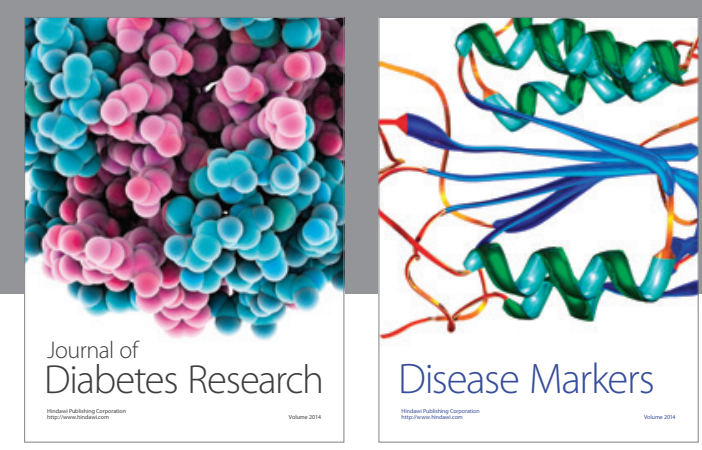

Disease Markers
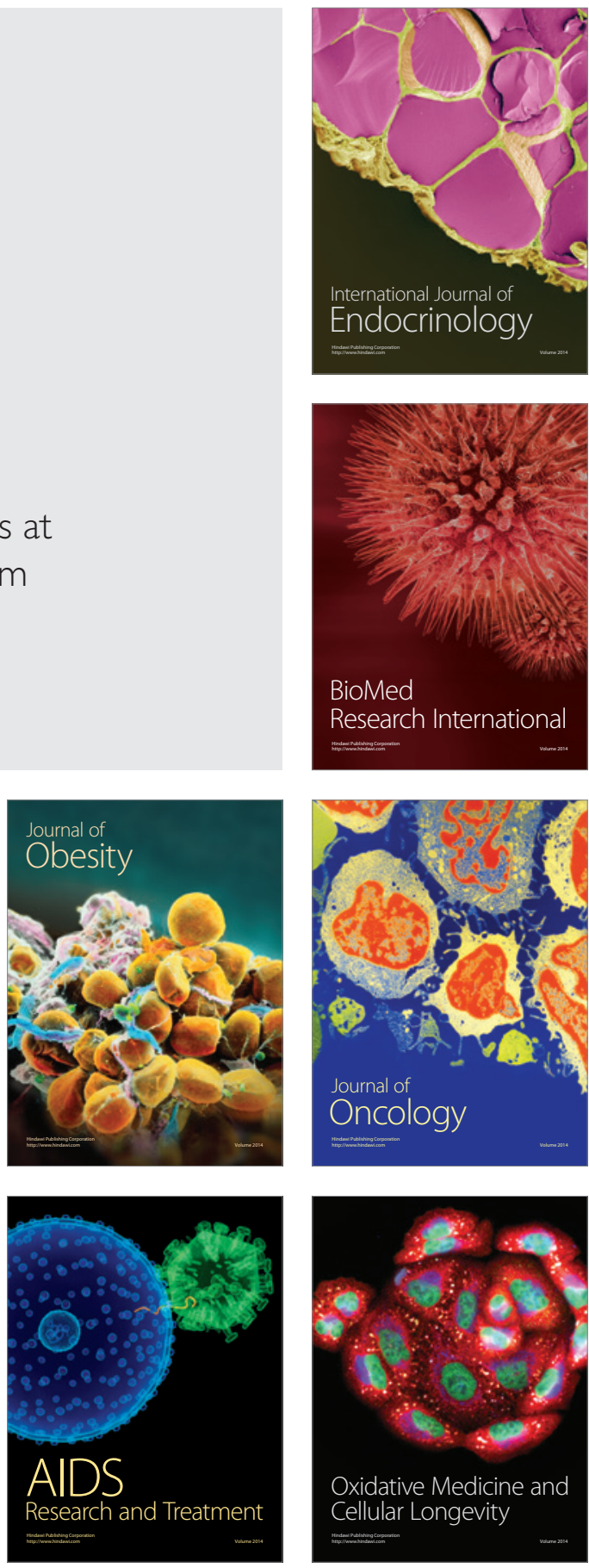